DOSSIÊ TEMÁTICO: Formação inicial de professores em contextos escolares e binômio teoria/prática nos estágios supervisionados

do/ https://doi.org/10.22481/rpe.v16i43.6838

\title{
DA FORMAÇÃO INICIAL DO PROFESSOR AO ESTÁGIO: OS DIFERENTES OLHARES SOBRE A PRODUÇÃO CIENTÍFICA NA AMÉRICA LATINA
}

\author{
FROM THE INITIAL EDUCATION OF THE TEACHER TO THE INTERNSHIP: THE \\ DIFFERENT VIEWS ON SCIENTIFIC PRODUCTION IN LATIN AMERICA
}

\author{
DE LA EDUCACIÓN INICIAL DEL PROFESOR A LA PRÁCTICA DOCENTE: LAS \\ DISTINTAS OPINIONES SOBRE LA PRODUCCIÓN CIENTÍFICA EN AMÉRICA \\ LATINA
}

\author{
Evandro Ghedin \\ Universidade Federal do Amazonas - Brasil \\ Maria Leogete Joca da Costa \\ Universidade Federal de Roraima - Brasil
}

\begin{abstract}
Patrik Marques dos Santos
Instituto Federal de Educação, Ciência e Tecnologia do Amazonas - Brasil
\end{abstract}

\begin{abstract}
Resumo: Este estudo guiou-se pela questão: O que diz a produção científica desenvolvida nos países da América Latina sobre as concepções e critérios da formação inicial de professores e do estágio nos cursos de licenciaturas? Teve-se como objetivo: fazer um levantamento nos Bancos de busca sobre a formação inicial de professores e o estágio; Conhecer e analisar a produção científica sobre a formação inicial de professores e o estágio dos cursos de licenciaturas no período de 2009 a 2019; Mapear as concepções e os critérios da formação inicial de professores e do estágio dos cursos de licenciaturas nos países da América Latina. A investigação é de cunho qualitativo, apoiada aos procedimentos metodológicos da pesquisa documental utilizando-se o software STArt, para obtenção das fontes e a hermenêutica crítica como analise. Deste levantamento obteve-se que o estágio supervisionado obrigatório, nas licenciaturas, já apesenta traços que mensuram o desenvolvimento dessa atividade formativa associada à pesquisa, embora sem nenhuma regularidade no Plano pedagógico dos cursos. Em contrapartida a analise nos permite ver que o estágio vem sendo realizado, predominantemente, pela racionalidade técnica, visto que é mais evidente a ausência de prática formativa docente conectada com a pesquisa enquanto elemento estruturante da formação. Considera-se que a formação docente necessita de políticas educacionais capazes de estruturar e estabelecer condições para que o estágio ocorra via pesquisa anuindo um cenário formativo em que professores formadores e em formação se atraiam pelo ato de se constituírem como sujeitos do conhecimento, mas com posturas epistemológicas que lhes permitam entender e compreender os processos formativos e a construção da identidade profissional docente na lógica cognitiva e humanitária.
\end{abstract}

Palavras chave: América Latina. Estágio Supervisionado. Formação inicial de professores.

Abstract: The preparation of this study was guided by the question: What does the scientific production developed in the countries of Latin America say about the conceptions and criteria of 
initial teacher training and internship in undergraduate courses in the period from 2009 to 2019 ? With the objective of making a survey in the search banks on the initial teacher training and the internship; To know and analyze the scientific production on the initial training of teachers and the internship of undergraduate courses in the period from 2009 to 2019; Map the conceptions and criteria of initial teacher training and the stage of undergraduate courses in Latin American countries. The investigation is of a qualitative nature, supported by the methodological procedures of the bibliographic research using the software STArt. From this survey, it was obtained that the mandatory supervised internship in undergraduate courses already has traits that measure the development of this training activity associated with research, although without any regularity in the pedagogical plan of the courses. On the other hand, between the lines also allows us to see that the internship has been carried out in the predominance of technical rationality, since it is more evident the absence of teaching training practice connected with research as a structuring element of the training itself. In view of the above, it is considered that teacher education needs educational policies capable of structuring and establishing conditions for the internship to take place via research, thus creating a formative scenario in which teacher educators and trainees are attracted by the act of constituting themselves as subjects of knowledge, but with epistemological attitudes that allow them to understand and understand the formative processes and the construction of the professional teaching identity in the cognitive and humanitarian logic.

Keywords: Initial teacher training. Latin America. Supervised internship

Resumen: La preparación de este estudio fue guiada por la pregunta: ¿Qué dice la producción científica desarrollada en los países de América Latina sobre las concepciones y criterios de la formación inicial de profesores a la práctica en cursos de grado de profesores en el período de 2009 a 2019? Con el objetivo de realizar una encuesta en los bancos de búsqueda sobre la formación inicial del profesorado y la práctica docente; Conocer y analizar la producción científica sobre la formación inicial de docentes y la práctica de cursos de grado de profesores en el período de 2009 a 2019; Mapear las concepciones y criterios de la formación inicial del profesorado y la práctica docente de cursos de grado en países de América Latina. La investigación es de naturaleza cualitativa, respaldada por los procedimientos metodológicos de la investigación bibliográfica que utiliza el software STArt. De esta encuesta, se obtuvo que la práctica docente supervisada obligatoria en cursos de grado ya tiene rasgos que miden el desarrollo de esta actividad de capacitación asociada con la investigación, aunque sin ninguna regularidad en el plan pedagógico de los cursos. Por otro lado, entre líneas también nos permite ver que la práctica docente se ha llevado a cabo en el predominio de la racionalidad técnica, ya que es más evidente la ausencia de prácticas de formación docente relacionadas con la investigación como elemento estructurante de la formación misma. En vista de lo anterior, se considera que la formación del profesorado necesita políticas educativas capaces de estructurar y establecer las condiciones para que la práctica docente se realice a través de la investigación, creando así un escenario formativo en el que los educadores de docentes y los aprendices se sienten atraídos por el acto de constituirse como sujetos de conocimiento. , pero con actitudes epistemológicas que les permiten comprender y comprender los procesos formativos y la construcción de la identidad docente profesional en la lógica cognitiva y humanitaria..

Palabras clave: América Latina. Formación inicial del professorado. Prácticas docentes supervisadas.

\section{Introdução}

A formação inicial de professores e o estágio, associado a todos os cursos de Licenciatura, são alvos de muitos debates e críticas em vários cenários políticos, econômicos, sociais e educacionais. As Instituições de Ensino Superior - IES - no Brasil, têm se 
debruçado para atender as demandas advindas dos cursos de licenciaturas e cumprir a legislação que rege a obrigatoriedade do Estágio Supervisionado.

Sendo a formação inicial de professores realizada pelas IES, o Ensino Superior é questionado sobre a orientação e as práticas do referido estágio das licenciaturas. Diante de tanta especulação e vozes aleatórias, nasce a necessidade de conhecer o processo formativo da docência e a concepção dada ao estágio nos países que compõem a América Latina.

Para isso, selecionaram-se bases de dados as quais tivessem aproximação entre os diferentes tipos de produção científica e permitissem a utilização da mesma string, objetivando encontrar trabalhos que contemplassem a formação inicial de professores e o estágio apenas nas licenciaturas da América Latina, direcionando as buscar para Bases da Dialnet, Periódicos da Capes, SciElo Latina, Science Direct e Web of Science.

A investigação é de cunho qualitativo, apoiando-se seus procedimentos metodológicos à pesquisa documental. Utilizou-se o software STArt ${ }^{l}$ (State of the Art), para auxiliar na sistematização de todas as informações extraídas das bases de dados mencionadas, contribuindo na composição deste Estado da Arte. As produções encontradas pela string de busca nas bases de dados englobaram diferentes gêneros textuais, tais como: teses, dissertações e artigos; porém, ao elencar os critérios delimitados para a pesquisa, entre período, local, idiomas e área, os resultados demonstrados apontaram somente artigos em ambas as buscas, justificando, assim, a ausência da produção científica centrada nos gêneros textuais: Teses e Dissertações.

Em obediência a um dos critérios para utilização do StArt, o protocolo preenchido norteou-se pela seguinte indagação: O que diz a produção científica desenvolvida nos países da América Latina sobre as concepções e critérios da formação inicial de professores e do estágio nos cursos de licenciaturas no período de 2009 a 2019? Seguido dos objetivos, a saber: fazer um levantamento nos Bancos de busca sobre a formação inicial de professores e o estágio; Conhecer e analisar a produção científica sobre a formação inicial de professores e o estágio dos cursos de licenciaturas no período de 2009 a 2019; Mapear as concepções e os critérios da formação inicial de professores e do estágio dos cursos de licenciaturas nos países da América Latina.

Quanto à descrição do protocolo, elemento obrigatório do software, far-se-á, portanto, no decorrer do texto, detalhamento de todos os critérios, bem como a exposição das palavras e termos utilizados na elaboração da string. Os trabalhos foram selecionados com a leitura

\footnotetext{
${ }^{1}$ Desenvolvido pelo Laboratório de pesquisa em engenharia de software da Universidade Federal de São Carlos no estado de São Paulo. Endereço eletrônico: http://lapes.dc.ufscar.br/tools/start_tool.
} 
apenas do Título e das Palavras-chave; para analisar e extrair os dados que respondiam à indagação desta proposta, a concentração da leitura deu-se no Resumo, Introdução e nas Considerações Finais ou Conclusão.

A sustentação teórica ancorou-se em Calderano (2017), Gatti et al. (2019), Ghedin, Oliveira e Almeida (2015), Pimenta e Lima (2014) e Saravia e Flores (2005) por entender que estes autores trazem contribuições epistemológicas indispensáveis para a reflexão que se apresenta.

\section{A formação inicial de professores e estágio nas licenciaturas: pontos e contrapontos no} cenário da América Latina

Refletir sobre os pontos e contrapontos da formação inicial de professores e o estágio nas licenciaturas, nos países da América Latina, é descortinar janelas que apontem as faces das políticas públicas voltadas para a docência e quais aspectos da formação dialogam historicamente, considerada a caracterização dos traços culturais desses países.

A princípio, seria mais do que necessário uma análise profunda sobre a cultura, a política e a educação de cada país para, consequentemente, nos debruçarmos na história da formação de professores e na maneira como é conduzida a orientação do estágio nas licenciaturas.

Dadas as reais condições, partiu-se para os fundamentos bibliográficos dos estudos de Gatti et al. (2019, p. 82) de onde se extrai que nos diferentes países da América Latina, a formação inicial possui cada qual a sua respectiva centralidade, ora no "desenvolvimento de conhecimentos gerais e de ampliação cultural dos futuros professores", ora na adesão de "atitudes para ensinar e educar", ora também por meio do ensino, promover "a consciência sobre a docência e sua contribuição para o progresso social, cultural e econômico das nações".

Saravia (2005) ao sistematizar uma análise sobre a formação de professores a partir dos diversos olhares de especialistas em 10 países da América Latina - Argentina, Bolívia, Colômbia, Chile, Cuba, Equador, Paraguai, Peru, Uruguai e Venezuela - conferiu que muitos aspectos nos cursos de formação de professores são comuns entre si. O autor já chamava atenção a respeito das políticas de formação e das propostas de ação educacionais apontado a urgência, em ambos os países, objetivando à melhoria no campo da formação inicial de professores, como se verifica a seguir:

[...] El desafío que tiene la formación inicial docente es la estructuración de um sistema que sea creativo, flexible y crítico, y se ofrezca en permanente 
actitud de búsqueda. Un programa de formación inicial para docentes debe estar n«abierto» a los constantes cambios, a los aportes de la ciencia, la cultura, la tecnología y la pedagogía, y a los debates, centrados en la realidad y su contexto. No debe ser terminal, sino articularse com otras formas de actualización permanente, como son los estudios de postgrado, las maestrías o los doctorados. [...] los estudiantes necesitan entender y comprender que enseñar requiere de algo más que de la apropiación y aplicación de procedimientos preestablecidos. La formación inicial de docentes es tanto una ciencia como un arte. Lo que es bueno para un grupo de educandos no lo es para otros; por ello, no se trata solo de conocer didácticas especializadas y aplicarlas. La gama de recursos que debe adoptar el futuro docente necesita contar con el desarrollo de opciones metodológicas y didácticas para obtener los resultados deseados. Además, y de manera fundamental, los alumnos de formación inicial docente requieren de principios básicos subyacentes a la explicación del desarrollo cognitivo y del aprendizaje humano. Un programa de formación inicial de docentes debe procurar que el futuro docente tenga una base teórica sólida para generar métodos didácticos consistentes con los mismos principios. Es decir, al aplicar el método didáctico que sea, el futuro docente debe entender por qué esse método facilita el aprendizaje (SARAVIA; FLORES, 2005, p. 36-37).

Após uma década e meia, os dizeres dos autores continuam em evidência, isso se confere neste atual Estado da Arte, após sistematização dos dados extraídos nas bases de dados mencionadas, não se registrou nos artigos nenhuma menção à formação inicial do professor como categorizou Saravia e Flores (2005, p. 37), a formação inicial de professores como sendo uma "uma ciência e uma arte".

Nosso olhar converge para mesma ótica dos autores, a estruturação do sistema de formação inicial de professores necessita ocorrer de maneira criativa e flexível, aberta às mudanças para a Ciência, em consonância com as entidades científicas, culturais e históricas as quais deveriam nortear as políticas de formação docente frente às tensões políticopartidárias - e aqui se faz referência especificamente ao Brasil.

É no processo de formação inicial que o futuro professor necessita aprender a desenvolver mecanismos metodológicos e didáticos, visto que a importância não é apenas conhecer a didática e aplicá-la. A partir da reflexão de Saravia e Flores (2005) para que a formação inicial de professores seja "uma ciência e uma arte", cabe a ela garantir aos alunos das licenciaturas conhecer e compreender princípios básicos subjacentes à explicação do desenvolvimento cognitivo e da aprendizagem humana. E de fato, esse pensamento ficou evidente nos registros, nas análises e compreensões, dos autores:

El programa de formación inicial docente debe renovarse de manera continua a partir de los problemas que suscita el proceso de enseñanzaaprendizaje y los nuevos problemas a afrontar. En la actualidad, es clave que los alumnos aprendan a desarrollar procesos cognitivos para aplicarlos a situaciones diferentes e inéditas, y no se limiten a la adquisición de 
determinados conocimientos. Aquí surge una nueva función docente en la que deben ser preparados: la competencia. La competencia es adquirir una capacidad, que no es calificación; ya que combina pericia con comportamiento social. Es algo más que una habilidad: es el dominio de procesos y métodos para aprender de la práctica, de la experiencia y de la intersubjetividad (SARAVAI; FLORES, 2005, p. 39-40).

Isso se reforça nos estudos de Gatti et al. (2019, p. 84) ao afirmar que a formação inicial deve levar os futuros professores a "compreenderem que ensinar requer algo mais que a apropriação e aplicação de procedimentos pedagógicos", a tomada de consciência sobre a "natureza do ensino e dos diferenciais de aprendizagem" é a essência maior do processo formativo, visto que zelar pelo desenvolvimento intelectual do estudante é lograr êxito no trabalho docente.

Em síntese, os autores apenas reafirmam que a base teórica quando bem consolidada, ou seja, quando o futuro professor conhece o porquê das metodologias de ensino e não apenas descobre como usá-las, o trabalho docente será diferenciado em todos os aspectos porque, neste caso, para se conhecer é preciso desenvolver a capacidade investigativa, e para investigar é preciso pesquisar, daí a importância do trabalho docente desenvolvido nas instituições de ensino superior acontecer associado com a pesquisa, referência dada a estudos já realizados no Brasil, como se pode destacar nos estudos de Pimenta e Lima (2014) e de Ghedin, Oliveira e Almeida (2015).

Por outro lado, não se pode negar os achados de Louzano e Moricone (2014) e Saravia (2005) interpretados por Gatti et al. (2019, p. 86) a respeito dos contrapontos encontrados nos cursos de graduação voltados para a formação inicial de professores nos mais diversos países da América Latina, de onde se extrai: "há variações substanciais entre os países latinoamericanos quanto ao tipo de instituição em que essa formação se dá", bem como para que etapa educacional o futuro professor seja preparado para atuação - sendo elas, Ensino Fundamental I e II e Ensino Médio, nomenclaturas dadas às etapas, posteriores à Educação Infantil, que compõem a Educação Básica no Brasil.

[...] há diversidade quanto às formas de oferta de formação inicial para professores, bem como nas exigências de entrada nos cursos e de estudos a serem realizados, e diferenças nas propostas curriculares e tempo de duração necessário até a titulação (GATTI et al, 2019, p. 86).

Diante da diversidade apresentada, e em se tratando de Brasil, onde há um leque de pesquisas focando a formação inicial de professores e nisso se inclui o estágio, marco inicial para a socialização profissional, cultural e científica da docência, é relevante trazer para este debate, as palavras de Granville (2008, p. 21) em que "propõe uma formação de professores 
baseada na reflexão sistemática", visto que a educação é um campo minado pela pluralidade e subjetividade, "portanto, cheio de contradições que emergem quase sempre do ponto de vista metodológico, sociológico, da sua utilidade e função", entre elas preparar o futuro professor, razão que justifica dizer que o estágio também seja diferente em todos os países, embora com pontos convergentes, tais como, numa perspectiva dialética e investigatória como já mencionado por Pimenta e Lima (2014) e Ghedin (2006).

Gatti et al. (2019, p. 91) ainda traz outra contribuição ao apontar que há diversos documentos, embora não especificados, de países da América Latina recomendando que os estágios na docência aconteçam associados aos cursos de licenciaturas, por entender que o objetivo é formar "trabalhadores que serão profissionais nas redes de ensino instituídas".

A autora também deixa claro que a formação inicial dos professores realizada nas Instituições de Ensino Superior "vem sendo questionada por razão do descuido com os estágios dos estudantes, exigidos nos diversos cursos em alguns países" (GATTI et al., 2019, p. 91). Ao se fazer uso dos pronomes indefinidos "diversos" e "alguns", ressalta-se, aqui, a falta de dados que identifiquem respectivamente os cursos e os países.

\section{Concepções e critérios da formação inicial de professores ao estágio}

Os estudos de Pimenta e Lima (2014, p. 29) discutem as concepções de estágio a partir dos conceitos de prática e práxis, apresentando-o como o campo de conhecimento, o que "significa atribuir-lhe um estatuto epistemológico que supere sua tradicional redução à atividade prática instrumental”.

Nessa discussão, a prática é "imitação de modelos", é a "instrumentalização teórica", ou seja, o estágio passa a ser visto como possibilidade de superação do hiato existente entre a teoria e a prática, concebendo-o como "aproximação da realidade e atividade teórica", além de apontar a "pesquisa" como método na formação do futuro professor, como é anunciado pelas autoras. "O Campo do conhecimento que se produz na interação entre cursos de formação e o campo social no qual se desenvolvem as práticas educativas, o estágio pode se construir em atividade de pesquisa".

Também é relevante ressaltar o dito por Freire (2001) quando se fundamentou nas bases epistemológicas de Liston e Zeicher (1991) e de Habermas (1982), para ilustrar, respectivamente, a formação inicial de professores e a construção do conhecimento vislumbrando conceber o estágio como sendo: aplicação da teoria, prática profissional e emancipação profissional. 
A primeira concepção no olhar de Freire (2001, p. 4) está implícita a ideia de que "os professores competentes possuem um conhecimento profundo, quer dos assuntos científicos de ensino, quer das estratégias de ensino que lhes permite criar situações de aprendizagem para os seus alunos".

$\mathrm{Na}$ segunda, os futuros professores ganham conhecimento profissional à medida que vão realizando as diferentes atividades docentes, visto que o estagiário é um aprendiz da profissão docente e, nessa condição, a aprendizagem emerge da prática em sala de aula, "no desempenho do ofício, observando o mestre a realizar as aulas e aceitando as sugestões dele quando é observado na situação de ensinar” (FREIRE, 2001, p. 9).

E na terceira, ainda na ótica de Freire (2001, p. 15), o estágio pedagógico "pressupõe a criação de condições que propiciem a reflexão sobre a acção, atendendo aos contextos onde esta se desenrola e às consequências das acções, quer para o desenvolvimento pessoal e social dos alunos, quer para a construção de uma sociedade".

Toda essa gama de discussão nos faz pensar em uma formação inicial de professores com palcos condicionantes para o envolvimento dos estagiários em práticas reflexivas, investigatórias, aliadas com a pesquisa como já citado e, aqui, reforçado por Ghedin (2006, p. 232) ao afirmar que "a dinâmica de um processo formativo interdisciplinar em que o estágio vincula-se à pesquisa objetiva formar o professor, como profissional reflexivo, capaz de compreender e atuar na realidade educacional", além de possibilitar, via estágio, ao futuro professor, a descoberta de alternativas pedagógicas para atuação em contextos contemporâneos tão diversos e conflitantes.

Esse vínculo entre o estágio e pesquisa Almeida (2008, p. 86) declarou ser "uma das formas de fazer os professores em formação aproximarem a realidade na qual atuarão aos discursos teóricos que têm acesso", visto que para Ghedin (2006, p. 234) a formação inicial do professor dada sobre "a reflexão na ação e sobre a ação, ao mesmo tempo que valoriza a prática docente como fonte de pesquisa e de autonomia do professor dá a este a responsabilidade por seu desenvolvimento profissional”.

De fato, os estágios curriculares nas licenciaturas precisam ser:

[...] reconhecidos, valorizados e planejados como uma etapa da formação em que, além da observação e coleta de dados para análise da realidade em que são desenvolvidos, os futuros professores tivessem a oportunidade de exercer o ofício docente, por meio de práticas supervisionadas, por um longo tempo, previstas em um projeto elaborado com corresponsabilidade entre instância formadora e escola-campo. [...] a socialização profissional começa na formação inicial, e é nessa etapa da formação que se fornecem as bases para que o profissional possa construir um conhecimento especializado, 
prevendo sua formação como um processo contínuo de desenvolvimento profissional durante o qual vai se configurando sua identidade docente (SILVESTRE; PLACCO, 2011, p. 33).

Assim, faz sentido reconhecer o estágio curricular na perceptiva da racionalidade crítica como dizem Silvestre e Placco (2001, p. 39) compreendendo-o "à luz das relações sociais estabelecidas pela estrutura social na qual se insere o processo educativo possuindo a ciência como referencial".

Já os estudos de Calderano (2017, p. 64) trazem uma concepção de estágio denominada "docência compartilhada", cujo entrelaçamento se dá pela escola e a universidade, pela teoria e prática, pela formação e o trabalho docente, a qual emergiu da prática educacional. A autora ainda explica que "tanto a formação quanto o trabalho docente são desenvolvidos simultaneamente pelos professores da universidade e da escola" e que o processo de formação inicial ocorre "nos dois campos, os quais são ligados dialeticamente".

Os dizeres da autora coadunam com os de Pimenta e Lima (2014, p. 56) quando sustentam que o estágio "prepara para um trabalho coletivo, visto que o ensino não é um assunto individual do professor, pois a tarefa escolar é resultado das ações coletivas dos professores e das práticas institucionais, situadas em contextos sociais, históricos e culturais".

Realmente, é desafiador proceder nesse intercâmbio durante o percurso formativo; o estágio precisa ocorrer nessa alternância do que se teoriza e o que se pratica em ambos espaços - universidades e escolas de Educação Básica - envolvendo todas as disciplinas da licenciatura (PIMENTA e LIMA, p. 56) “constituindo um verdadeiro e articulado projeto político-pedagógico de formação de professores cuja marca é alavancar o estágio com pesquisa".

\section{A produção científica na América Latina sobre a formação inicial de professores e do estágio nas licenciaturas no período de 2009 a 2019}

Como proposto em um dos objetivos deste trabalho, conhecer e analisar a produção científica sobre a formação inicial de professores e o estágio, dos cursos de licenciaturas da América Latina, no período de 2009 a 2019, faz necessário apresentar o quadro referendando os bancos de busca, os critérios de refinamento e a data de acesso para situar o leitor. 
Quadro 1: Critérios de refinamento de busca

\begin{tabular}{|c|c|c|c|c|c|c|}
\hline $\begin{array}{l}\text { Critérios de } \\
\text { refinamento } \\
\text { Buscas }\end{array}$ & 飠 & 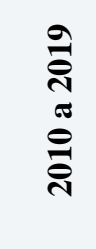 & 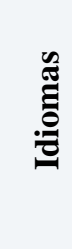 & 胥 & 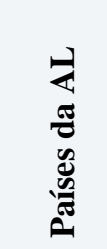 & 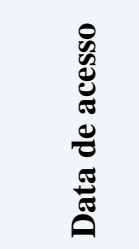 \\
\hline Dialnet & 249 & 218 & 211 & 211 & 144 & $05 / 01 / 20$ \\
\hline Periódicos da Capes & 668 & 545 & 213 & 213 & $141 * *$ & $07 / 01 / 20$ \\
\hline SciElo & 128 & 109 & 101 & 56 & 52 & $05 / 01 / 20$ \\
\hline Science Direct & 52 & 50 & $*$ & 9 & $9 * *$ & $08 / 01 / 20$ \\
\hline Scopus & 5 & 5 & 4 & 4 & 4 & $05 / 01 / 20$ \\
\hline Web of Science & 114 & 98 & 90 & 57 & 48 & $08 / 01 / 20$ \\
\hline Total de rabalhos & 1.330 & 1.025 & 619 & 550 & 397 & \\
\hline
\end{tabular}

Para a construção da amostragem, elaborou-se uma string utilizando os Operadores booleanos OR, AND e AND NOT, os quais ajudaram a sistematizar os primeiros resultados, que a partir desses, foram aplicados filtros e/ou critérios para refiná-los, e, assim, construir o objeto de estudo desta pesquisa.

Dada a string ("formação inicial de professores" OR "formación inicial del profesorado" OR grado OR licenciatura) AND (estágio OR pasantía) AND NOT (pedagogia AND pedagogía), com resultados preliminares, foi possível visualizar uma vasta produção científica destacando os seguintes gêneros textuais: Teses, Dissertações, Artigos, Ensaios e Resenhas de livros. Porém, com a aplicação dos critérios de refinamento, de inclusão e exclusão, observou-se a ausência dos dois primeiros gêneros mencionados nos resultados finais da busca.

Além disso, as bases de buscas disponibilizavam a extração das informações por meio de arquivos de referência de importação, ou seja, extensões denominadas de "bibtex e ris", as quais facilitaram a inserção de todas as informações na ferramenta StArt. É importante salientar que essas extensões disponibilizadas nas bases de busca possibilitaram agilizar os procedimentos previstos na Revisão Sistemática, principalmente, pelo fato do software utilizado para isso, o StArt, aceitá-las. No gráfico 01, visualiza-se a descrição quantitativa dos textos inseridos, além da sistematização deles no StArt. 
Gráfico 01: Resultado do quantitativo de artigos no tratamento metodológico da Revisão Sistemática

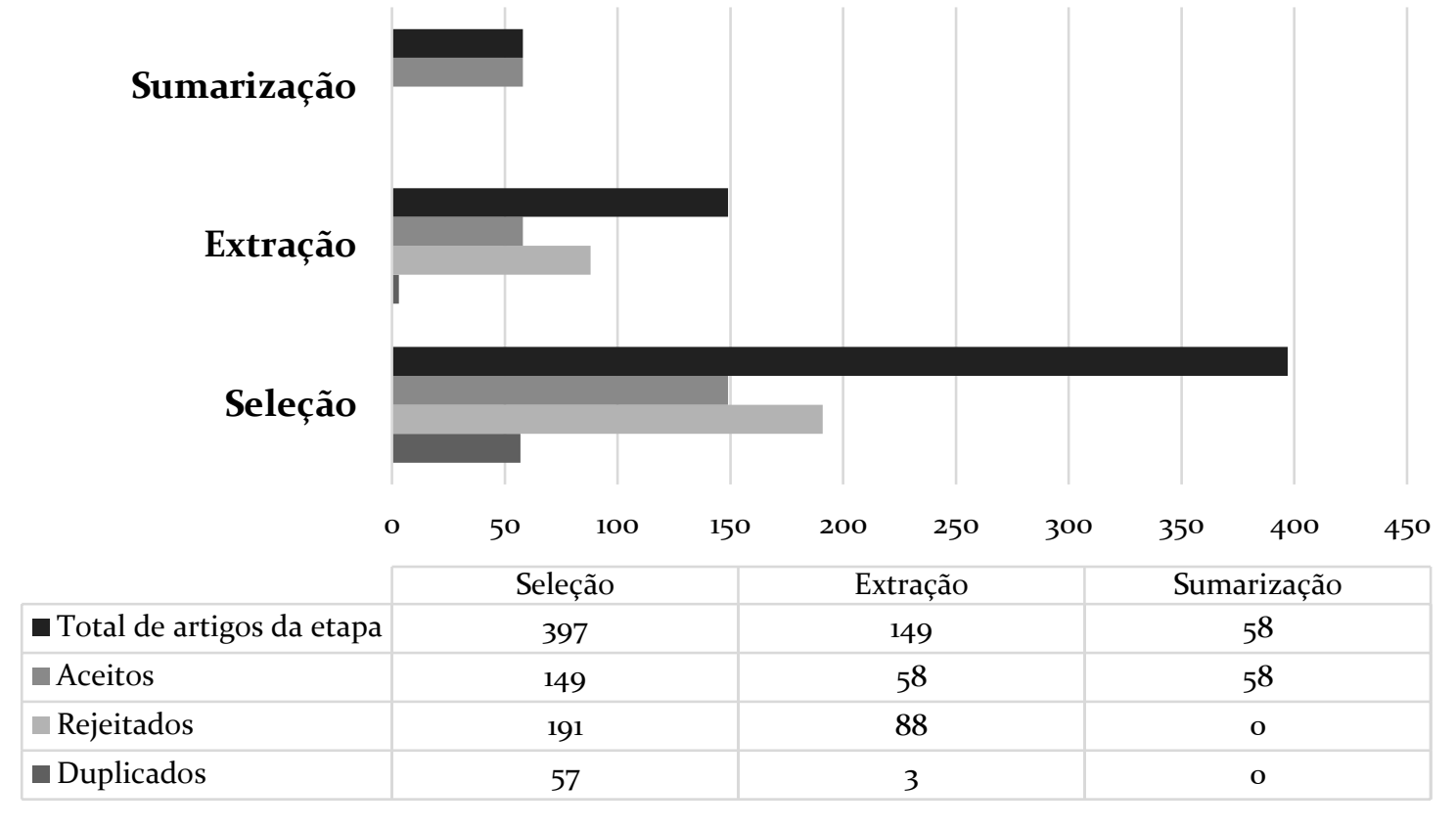

Fonte: Dados resultantes da investigação dos autores

No protocolo, elegeram-se os critérios de Inclusão (I) Formação inicial de professores; Formação docente; Formação de professores; Estágio; Estágio Supervisado; Estágio curricular; Estágio docente; de Exclusão (E) Formação contínua; Pedagogia; Anos inicias; Prática docente e Prática de ensino para se chegar a esse quantitativo de 397 artigos.

A seleção ocorreu com a identificação dos termos, preestabelecidos na string, encontrados no Título, Resumo e Palavras-chave. Dos 397 selecionados, 191 foram rejeitados; 57 eram em duplicidade e apenas 149 foram aceitos e passaram para a fase de Extração.

$\mathrm{Na}$ fase da Extração, os 149 artigos passaram por uma filtragem de onde se obteve o status de 3 trabalhos em duplicidade e apenas 58 aceitos. Aqui, a leitura já se estendia ao Resumo, à Introdução e às Considerações finais/Conclusão o que resultou na rejeição de 88 trabalhos.

É interessante frisar que em todos os países da América Latina havia produção científica acerca do tema em pauta; porém, apenas em quatro deles, em função dos critérios de refinamento foi possível coletar textos, como se confere no quadro 02 : 
Quadro 2: Países da América Latina

\begin{tabular}{|c|c|c|c|c|c|}
\hline $\begin{array}{l}\text { Bancos de } \\
\text { Buscas }\end{array}$ & 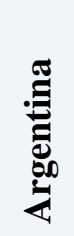 & $\begin{array}{l}\overline{\bar{v}} \\
\bar{\hbar} \\
\bar{n}\end{array}$ & $\frac{\frac{\pi}{0}}{\frac{0}{\delta}}$ & 递 & 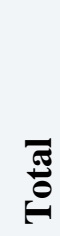 \\
\hline Dialnet & 2 & 30 & 1 & 1 & 33 \\
\hline Periódicos da Capes & 1 & 11 & 1 & - & 13 \\
\hline SciElo & - & 9 & - & 1 & 10 \\
\hline Science Direct & - & - & - & - & 0 \\
\hline Scopus & - & 1 & - & - & 1 \\
\hline Web of Science & - & 1 & - & - & 1 \\
\hline
\end{tabular}

Fonte: Dados da investigação dos autores

O Brasil foi o país com maior número de artigos publicados (52); seguido da Argentina com (3) e os países Colômbia e Costa Rica com a mesma quantidade (2). É interessante ressaltar que em todos os países, mesmo em anos e cursos de licenciaturas distintos, há convergências em comum nesses achados, entre as quais se destacam:

[...] a construção da identidade profissional do futuro professor seja pensada e elaborada não somente em relação à prática, mas envolvida num conjunto de ações que lhe permitirão ampliar os horizontes de sua compreensão e de sua atuação no campo de trabalho, orientando-se pela construção do conhecimento a partir de um processo sistemático e metódico de pesquisa. (GHEDIN; OLIVEIRA; ALMEIDA, 2015, p. 169).

A pesquisa associada ao estágio compareceu nas Considerações finais/Conclusão coadunando com os autores. Ficando claro que em ambos os países, a necessidade de se adotar a pesquisa como categoria de articulação entre prática versus teoria seria a mais eficiente maneira de revelar a competência técnica e o engajamento político-social da práxis docente. Essa intepretação se comprova com os seguintes dizeres:

O professor em formação está se preparando para efetivar as tarefas práticas de ser professor, Dado que não se trata de formá-lo como reprodutor de modelos práticos dominantes, mas capaz de desenvolver a atividade material para transformar o mundo natural e social humano, cumpre investigar qual a contribuição que o estágio profissional pode dar nessa formação. (GHEDIN; OLIVEIRA; ALMEIDA, 2015, p. 170).

E em se tratando de estágio e formação inicial do professor, contabilizou-se 14 cursos de licenciaturas, como se verifica no quadro 3, nas mais diversas áreas do conhecimento: 
Quadro 3: Formação inicial do professor / Estágio por curso

\begin{tabular}{|c|c|c|c|c|c|c|c|c|c|c|c|c|c|c|c|}
\hline & \multicolumn{15}{|c|}{ Licenciaturas } \\
\hline Bancos de Buscas & 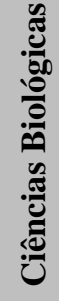 & 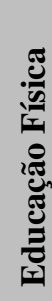 & 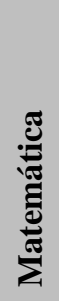 & 宽 & 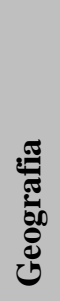 & 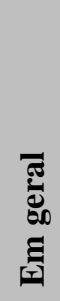 & 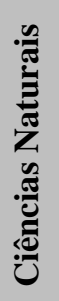 & 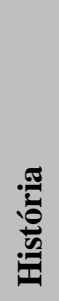 & 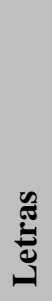 & 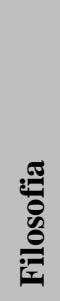 & 苛 & 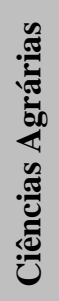 & 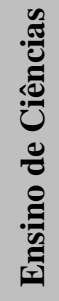 & 苞 & 晋 \\
\hline Dialnet & 8 & 5 & 4 & 3 & 4 & 1 & 1 & 2 & - & 1 & 2 & 1 & - & 1 & 33 \\
\hline Periódicos da Capes & - & 1 & 3 & 2 & 1 & - & 2 & 1 & 2 & 1 & - & - & - & - & 13 \\
\hline SciElo & 2 & 2 & 1 & - & - & 3 & 1 & - & - & - & - & - & 1 & - & 10 \\
\hline Science Direct & - & - & - & - & - & - & - & - & - & - & - & - & - & - & 0 \\
\hline Scopus & - & 1 & - & - & - & - & - & - & - & - & - & - & - & - & 1 \\
\hline Web of Science & - & - & - & - & - & - & - & - & 1 & - & - & - & - & - & 1 \\
\hline Quantidade por curso & 10 & 9 & 8 & 5 & 5 & 4 & 4 & 3 & 3 & 2 & 2 & 1 & 1 & 1 & 58 \\
\hline
\end{tabular}

Fonte: Dados da investigação dos autores

Da tabela apresentada, descreve-se por ordem decrescente, as quatorze licenciaturas, sendo as Ciências Biológicas a licenciatura com maior expressividade na produção científica com 10 artigos; seguida de Educação Física com 09, Matemática com 8; Geografia e Física com 5 artigos; Ciências Naturais com 4 artigos; História com 3; Ciências Agrárias, Filosofia e Química ambas com a mesma quantidade 02; Ensino de Ciências com 1.

Somando-se a esse quantitativo expresso, em 4 trabalhos não foi possível identificar o curso específico, nos elementos textuais selecionados, tais como: Título, Resumo, Introdução e Considerações Finais/Conclusões. No entanto, é válido esclarecer que o estágio supervisionado e a formação inicial do professor compareceram referendando "as licenciaturas", mas sem especificar qual delas, razão que o agrupamento foi denominado de "Em geral".

Como o período de 2009 a 2019 foi um dos critérios adotado, com o gráfico 02 é possível visualizar as 58 publicações sistematizadas por ano e em ordem cronológica de publicação, embora não esteja especificado o país de origem dos artigos. 
Gráfico 02: Quantidade de artigo por ano

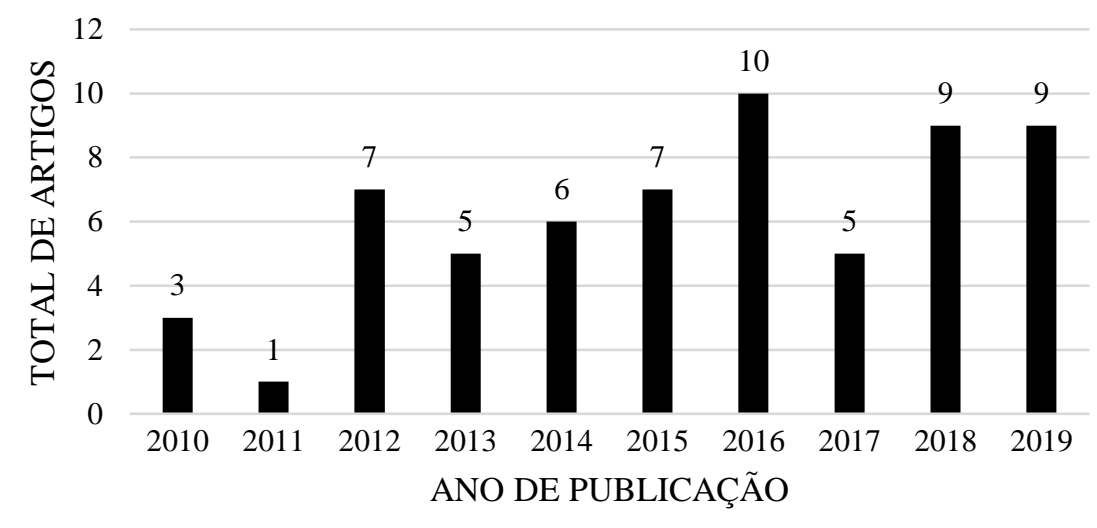

Fonte: Dados da investigação dos autores

Os artigos publicados no ano de 2010 são de três países distintos, Argentina, Brasil e Colômbia, também são de licenciaturas diferentes. Dois deles apresentam semelhança ao focar a formação inicial do professor como um processo desarticulado da prática do estágio e que o estágio ocorre apenas para cumprir os créditos obrigatórios dos cursos.

Enquanto que o publicado, no Brasil, de autoria de Caimi (2009, p. 27) afirma a necessidade de acentuar o compromisso da licenciatura com a formação "de um profissional reflexivo, capaz de compreender tanto os seus processos cognitivos quanto os de seus alunos", e que apesar de já existir estudos sobre a cognição, em se tratando de formação de professores “ainda não é suficientemente explorado na produção acadêmica brasileira", é preciso a formação docente possibilitar ao futuro professor a ser um "investigador prático-reflexivo" sobre o próprio exercício em sala de aula.

Já o único trabalho publicado em 2011 apontava uma crise conceitual vivida no Ensino Superior apresentando a licenciatura como curso de preparação para o mercado de trabalho e o estágio como condicionante para a obtenção de título de licenciado.

Essa primeira leitura vislumbra o sinalizado por Gatti e Barreto (2009, p. 294) que os Projetos Pedagógicos dos cursos de Licenciaturas nas IES, no Brasil, não tinham clareza no modo como o estágio é estruturado. Na reflexão das autoras, essa ausência podia sinalizar duas possibilidades, uma que os "estágios são considerados como uma atividade à parte do currículo" ou "sua realização é considerada como aspecto meramente formal".

A conclusão feita por elas se confirmam também em nosso estudo, não somente nos detalhados nos anos de 2010 e 2011; dos 58 trabalhados analisados, fugindo da ordem cronológica, 5 deles apontaram para a primeira possibilidade; e em 8, foi detectado apenas o cumprimento do aspecto obrigatório, em outras palavras, "meramente formal". 
A ausência de clareza nos projetos dos cursos de licenciaturas e essa consideração do estágio "como uma atividade docente à parte do currículo" (grifo nosso) se estendem também aos outros países da América do Sul e não só ao Brasil. Por isso é pertinente refletir sobre os cursos de formação inicial de professores, em especial, no que diz respeito a estrutura do estágio enquanto componente curricular obrigatório, como se observa na seguinte afirmação:

Apesar de o estágio curricular constitui-se componente obrigatório do
currículo dos cursos de formação docente, as informações relativas à sua
oferta, ementa, distribuição da carga horária, bem como proposta
institucional relativa a seu desenvolvimento - essas informações não são
objetos claros e definidos nas formulações dos projetos pedagógicos dos
cursos. (CALDERANO, 2017, p. 61).

De fato, a afirmação da autora é comprovada no decorrer desta pesquisa. Nos trabalhos analisados, mesmo comparecendo as normas e resoluções, em suma, a legislação que rege o estágio nas licenciaturas, não foram detectadas as informações necessárias de definição do estágio, visto que boa parte dos artigos faziam referências às disciplinas específicas do estágio.

Os termos "articulação", "interlocução", "troca de saberes" e "construção de saberes" definem os trabalhos publicados no ano de 2012, embora associados a categorias distintas elencadas nos critérios de inclusão, como se detalha a seguir: a formação compareceu como espaço de troca de saberes e o estágio como elemento articulador entre a instituição de ensino superior - IES e a escola de educação básica - EEB; A construção de saberes também foi atribuída a formação do professor, dando destaque ao estágio como uma interlocução consistente entre as ações de pesquisar e de ensinar.

Há também incertezas e até contradições nesses achados em relação à formação inicial de professores e ao estágio supervisionado das licenciaturas. E isso vai de encontro com o já apontado por Saravia, (2005, p. 36) em seu estudo sobre a formação inicial docente em países da América Latina, em que destacou a merecida atenção para as políticas e propostas de formação, as quais ainda são descontínuas e carentes de ações centradas na estrutura, como bem reafirmaram Gatti e Barreto (2009) e Calderano (2017) visto serem os cursos de professores que formam os futuros professores para atuarem na Educação Básica, por isso as licenciaturas necessitam, segundo Gatti et al. (2019, p. 84) "estruturar um sistema de formação mais criativo, flexível e crítico, centrado na realidade e em seu contexto, aberto às mudanças no campo da ciência" bem como "avaliar constantemente os currículos da formação inicial dos docentes". 
Isso posto, é válido evidenciar que a questão da formação de professores ultrapassa a necessidade de refletir e compreender os processos cognitivos do professor, como abordou Caimi (2009), o foco da docência, enquanto campo de "troca e ou (re)construção de saberes" (grifo nosso), ganhando uma dimensão mais abrangente porque se torna:

[...] um problema social na medida de sua relevância e por conta do trato incerto que tem merecido mediante políticas descontinuadas e pela pouca discussão social relativa a seu valor social concreto na contemporaneidade, bem como sobre os fundamentos dessa formação e das práticas a ela associadas. (GATTI, et al., 2019 p. 11).

Os estudos de Dourado (2016, p. 29) confirmam a centralidade do problema social na formação docente, no tocante à descontinuidade das políticas públicas educacionais, ao elencarem a existência das incongruências estruturais no que diz respeito "aos lócus de formação, ao projeto de formação, ao papel do professor, à dinâmica formativa, à relação teoria e prática,", além de destacar incompatibilidade ao "papel dos estágios supervionados, à prática como componente curricular" nos cursos de licenciaturas especificamente no Brasil.

A reflexão trazida pelos autores nos faz compreender o porquê das divergências conceituais referentes ao estágio supervisionado e à formação inicial de professores, como se comprova nos achados em nossa pesquisa:

Figura 1: Achados da pesquisa

Ação desarticulada;
Prática dinâmica;
Promove relações mais
próximas entre escola e
universidade;
Conhecer a realidade da
escola;
Reflexão e criticidade;
Consolidação de
habilidades;
Vivência compartilhada.

Eixo articulador;

Prática complexa;

Dispõe de um menor vínculo com a escola;

Proximidade com a realidade educacional;

Concepção de racionalidade técnica;

Momento único;

Cumprimento dos requisitos para certificação profissional.

Fonte: Dados da investigação dos autores

O PIBID ${ }^{2}$ compareceu, em artigos publicados nos anos de 2013, 2016 e 2019, em circunstâncias diversas: ora em um paralelo comparativo com estágio; ora, embora sem tanta

\footnotetext{
${ }^{2}$ Programa Institucional de Bolsa de Iniciação à Docência - Pibid - criado e financiado pelo Ministério da Educação - MEC - por meio da Coordenação de Aperfeiçoamento de Pessoal Nível Superior - Capes instituído pela Portaria n. ${ }^{\circ}$ 38, de 12 de dezembro de 2007
} 
clareza textual, sugerindo a substituição pelo estágio; ora numa perspectiva de análise das políticas de formação docente entre os embates e contradições, limites e possibilidades a que se opõe o estágio supervisionado nos cursos de licenciaturas.

Sabe-se que o Pibid foi instituído para ocupar os mesmos espaços onde também ocorre o estágio supervisionado obrigatório. Não se pode negar as semelhanças em relação às atividades docentes; no entanto, é preciso ressaltar aspectos que os diferenciam, e isso fica claro a partir do peso semântico do adjetivo atribuído ao estágio "obrigatório".

Em outras palavras, o estágio é um componente curricular de todos os cursos de licenciaturas; enquanto que o Pibid - trata-se de um "programa", ou seja, uma política; portanto não atinge a todos das licenciaturas.

O PIBID não é componente curricular e conta com financiamento específico para a articulação entre escola e universidade na formação inicial de professores através de bolsa, em que professor da universidade, professor da educação básica e aluno de licenciatura recebem esse auxílio financeiro para desenvolverem seus projetos, e também contam com verba de custeio para suas atividades. (GIMENES, 2016, p. 127).

Como já dito, se é política há descontinuidade, além de não alcançar a todos como o estágio. Pimenta e Lima (2019, p. 6) afirmam que o "PIBID também se configura como uma política focal de curto alcance, uma vez que é destinado à pequena parcela de estudantes que cursam a licenciatura".

Visto que o eixo central deste estudo é a formação inicial do professor na perspectiva do estágio supervisionado das licenciaturas, é relevante observar a figura 2:

Figura 2: Formação inicial do professor e o estágio supervisionado na licenciatura

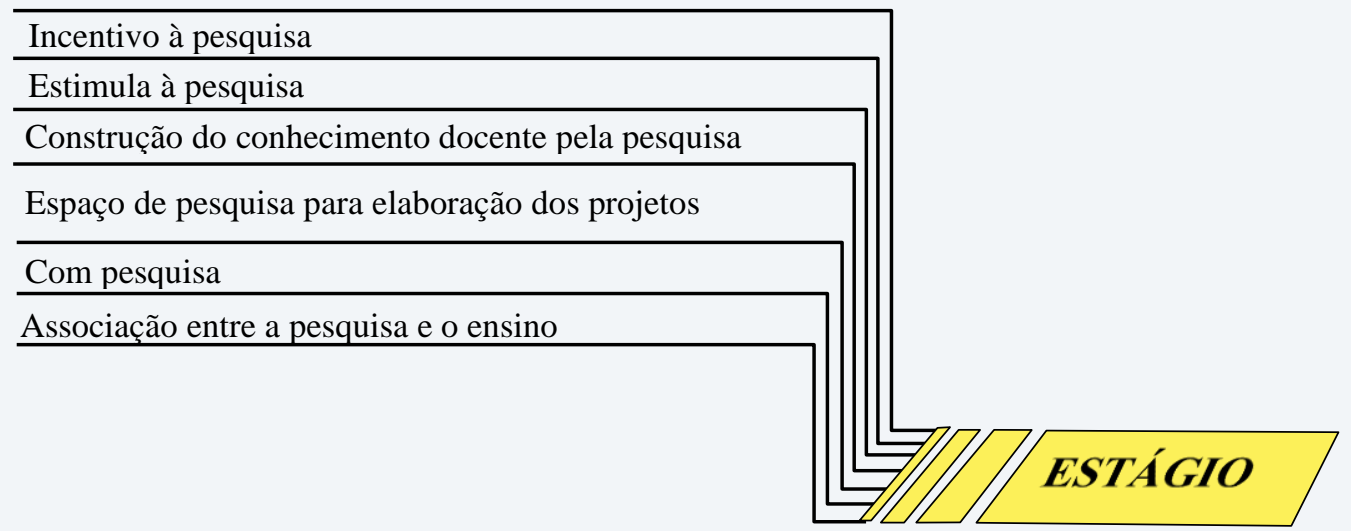

Fonte: Elaboração dos autores 
Os trabalhos que apresentaram o Estágio Supervisionado na docência como prática de "incentivo" e que "estimula" a pesquisa apontaram também preocupação por partes dos futuros professores. Há passagens reveladoras da importância de se aprender a pesquisar tanto nas disciplinas relacionadas com o estágio quanto na prática dele; no entanto, eles também revelaram que a ação de aprender a ensinar é fragilizada, detectou-se nesses achados que o processo da formação docente não forma os futuros professores para atuarem na Educação Básica, especificamente, do $6 .^{\circ}$ ao $9 .^{\circ}$ ano do Ensino Fundamental e nas 3 séries do Ensino Médio.

Esse tratamento dado à pesquisa no estágio na formação docente retrata a falta da clareza sobre o conceito de "pesquisa", enquanto conjunto de ações cuja finalidade é fortalecer a descoberta de caminhos para a construção do conhecimento e/ou aprofundamento e domínio dele.

De fato, o professor precisa compreender não só o conceito, mas vivenciar a pesquisa desde a formação inicial, porque o processo formativo do professor que:

[...] passa por uma formação de pesquisa é um elemento chave que pode possibilitar uma outra formação do professor que não seja aquela tradicional. Tradicional quer dizer aqui aquela formação onde o professor é um mero reprodutor das teorias e das ideologias que a sociedade econômica propõe ou que o capitalismo impõe ao professor e à sociedade. (GHEDIN; OLIVEIRA; ALMEIDA, 2015, p. 53).

A partir da fala dos autores, fica evidente que a formação docente alicerçada na e pela pesquisa, "foge do modelo tradicional", porque faculta a construção de novos saberes, e não tão somente os docentes, mas aqueles que perpassam os didático-pedagógicos pelo fato de se investigar o contexto educacional e, assim, aprender a analisar e interpretar a realidade do universo educacional em sua totalidade.

Alguns artigos revelaram o Estágio como a "Construção do conhecimento docente pela pesquisa"; enquanto outros traduziram como o "Espaço de pesquisa para elaboração dos projetos" e nessa caminhada de formação, percebe-se a ausência da compreensão dos conceitos "Estágio" e "Pesquisa", no processo formativo. Cabendo, aqui, uma reflexão a partir do dito por Gatti e Barreto (2009) e Calderano (2017) a respeito da falta de clareza de como o Estágio está estruturado nos projetos pedagógicos dos cursos das licenciaturas; bem como o conceito de Pesquisa na formação docente trazido por Ghedin, Oliveira e Almeida (2015, p. 53) "elemento chave na produção das ciências, na construção do conhecimento humano, na elaboração das técnicas e na formação de profissionais". 
No entanto, considerar o Estágio como "Espaço de pesquisa para elaboração dos projetos”, há uma inversão de sentido do próprio fazer docente e da ação de estagiar. Visto que durante o processo do estágio também se pode elaborar projetos, sendo eles pedagógicos, de leituras, de escrita, seja qual for a natureza; mas se restringir “a elaboração de" é limitar e/ou condicionar o estágio a práticas dissociadas do fazer docente do professor atuante da sala da aula da Educação Básica.

Por outro lado, aqueles que consideraram o estágio como a "Construção do conhecimento docente pela pesquisa" coadunam com os achados que apontaram que o Estágio Supervisionado nas licenciaturas deve ocorrer "com pesquisa". Isso sintetiza a fala de Caimi (2009) reforçada pelos seguintes dizeres:

\begin{abstract}
A pesquisa como princípio educativo e cognitivo nos conduz a uma nova compreensão e visão sobre o professor, pois à medida que o compreendemos e o formamos como sujeito do conhecimento, percebemos que ele não deve desempenhar uma função meramente técnica. Assim, o professor torna-se um sujeito que além de produzir seu próprio conhecimento, ele se torna aquele que também é construtor de seu próprio modo de ser e de fazer-se automaticamente à medida que produz o próprio conhecimento. (GHEDIN; OLIVEIRA; ALMEIDA, 2015, p. 54).
\end{abstract}

Ao se pensar no estágio como a "Construção do conhecimento docente pela pesquisa" e no estágio "com a pesquisa" é se perceber na sala de aula da Educação Básica e transcender a realidade material, concebendo a Educação Básica como o principal palco formativo do futuro professor e não se constituir apenas o pesquisador.

O desenvolvimento do estágio proposto nesses termos traduz uma ação coletiva, interdisciplinar e compartilhada como bem foi colocado por Calderano (2017). Além disso, quando a formação inicial docente ocorre, como disse Ghedin (2006, p. 232), num processo “interdisciplinar em que o estágio vincula-se à pesquisa", a essência formativa centraliza-se em "formar o professor, como profissional capaz de compreender e atuar na realidade educacional contemporânea e propor novas alternativas pedagógicas". Em suma, isso representa a verdadeira "associação entre o estágio, a pesquisa e o ensino."

\title{
Considerações Finais
}

O levantamento realizado obstinou em buscar produções em Bancos de dados e repositórios internacionais de impactos significativos na comunidade científica para identificar as discussões a respeito do estágio supervisionado e a formação inicial de professores para aproximações ao contexto da América Latina. 
Publicações de artigos foram as produções com maiores evidências, neste estudo, no uso dos critérios definidos no protocolo obrigatório da Revisão Sistemática - RS. Embora não denotadas nos dados discutidos, foram encontradas, na amostragem inicial, teses e dissertações relacionadas à temática; entretanto, devido às delimitações metodológicas expressadas na RS não compuseram a análise do levantamento realizado.

Por outro lado, afirmamos que os gêneros textuais ausentes na pesquisa podem comparecer para outros contextos e fontes, mas para os bancos de dados e repositórios que transcorreram o levantamento e os critérios utilizados não foi possível garantir tais produções no quantitativo da amostragem final.

Fazer este mapeamento foi necessário, visto que o estágio supervisionado e a formação inicial docente são elementos centrais do objeto de estudo de doutoramento do Programa de Pós-graduação da Universidade Federal do Amazonas. E como mencionado, em função do protocolo, não foi possível identificar as Instituições de Ensino Superior, mas encontrar rastros para a amostragem dos cursos, entre eles, destacam-se: Ciências Biológicas, Educação Física e Matemática, licenciaturas com maior registro sobre a temática no período de 2009 a 2019.

Com exceção do título, a seleção dos elementos textuais pontuados no protocolo, tais como: Título, Resumo, Introdução e Considerações Finais, o estágio compareceu associado a algumas categorias listadas nos critérios de Inclusão como: "Formação inicial de professores; Formação docente e Formação de professores", sem nenhum rastro que permitisse saber a qual curso de licenciatura se tratava; no entanto, os ditos, por meio das categorias, nos fez pensar que as reflexões trazidas nesses textos referiam-se às licenciaturas de modo generalizado.

Além do Brasil, dos países que compõem a América Latina, em apenas 3 foram filtradas as produções, a saber: Argentina, Colômbia e Costa Rica. Essa limitação está atribuída, em especial, aos idiomas escolhidos - Português e Espanhol. Entretanto, em relação à concepção de formação docente e às práticas de estágio supervisionado, os trabalhos mostraram as mesmas convergências e também divergências, ou seja, as pesquisas convergem para conclusões semelhantes quando se trata de formação inicial de professores e o estágio como seu processo central.

Apesar de não se ter olhado a estrutura dos cursos nas respectivas instituições, pela lente da produção, percebe-se que há certos avanços e outros ranços, mostrando a necessidade de integrar outras condições para que professores formadores e futuros professores possam não só se apropriar de conhecimentos científicos, didáticos, pedagógicos e metodológicos 
além daqueles de natureza ético-moral; mas sobretudo, da apropriação dos conhecimentos que emergem do patamar cultural e histórico, ou seja, uma formação docente mais humanizadora e equitativa.

Congraçamos da ideia de que a formação docente centraliza um problema de ordem política e social, isso se atesta nos rastros marcados pela incompatibilidade e divergência entre o que se faz antes e durante o estágio supervisionado nas licenciaturas e a falta de clareza no tocante à estrutura dele, enquanto componente curricular obrigatório.

De fato, o estágio supervisionado obrigatório, nas licenciaturas, já apresenta traços que mensuram o desenvolvimento dessa atividade formativa associada à pesquisa, embora sem nenhuma regularidade no Plano pedagógico dos cursos. Em contrapartida, as entrelinhas nos levam a pensar que elas também nos permitem ver que o estágio vem sendo realizado na predominância da racionalidade técnica, visto que é mais evidente a ausência de prática formativa docente conectada com a pesquisa enquanto elemento estruturante da própria formação.

Em suma, a formação docente necessita de políticas educacionais capazes de estruturar e estabelecer condições para que o estágio ocorra via pesquisa anuindo um cenário formativo em que professores formadores e futuros professores se atraiam pelo ato de se constituírem como sujeitos do conhecimento, mas com posturas epistemológicas que lhes permitam entender e compreender os processos formativos e a construção da identidade profissional docente na lógica cognitiva e humanitária.

\section{REFERÊNCIAS}

CAIMI, Flávia Eloisa. A aprendizagem profissional do professor de história: desafios da formação inicial. Fronteiras, Dourados, MS, v. 11, n. 20, p. 27-42, jul./dez. 2009. Disponível em; http://ojs.ufgd.edu.br/index.php/FRONTEIRAS/article/view/352. Acesso em 20 DE MAIO DE 2020.

CALDERANO, Maria da Assunção. O estágio curricular e docência compartilhada: na perspectiva do realismo. 1. ${ }^{\mathrm{a}}$ ed. Curitiba. Appris, 2017.

DOURADO, L. F. Formação de Profissionais do Magistério da Educação Básica: novas diretrizes e perspectivas. Comunicação \& Educação, a. 21, n. 1, p. 29, 2016.

FREIRE, Ana Maria. Concepções orientadoras do processo de aprendizagem do ensino de estágios pedagógicos. Colóquio: modelos e práticas de formação inicial de professores, Faculdade de Psicologia e de Ciências da Educação, Universidade de Lisboa. Lisboa, Portugal, 2001. Disponível em http://www.educ.fc.ul.pt/recentes/mpfip/pdfs/afreire.pdf. Acesso em 02 de janeiro de 2020. 
GATTI, Bernadete Angelina; BARRETO, Elba Siqueira de Sá. Professores no Brasil: impasse e desafios. Brasília: Unesco, 2009. P. 294.

GATTI, Bernardete et al., Professores do Brasil: novos cenários de formação. Brasília, UNESCO: 2019. Disponível em: https://unesdoc.unesco.org/search/3729ae6b-f73a-457a-8a65bad95098af50. Acesso em 27 de dezembro de 2020.

GHEDIN, E. A articulação entre estágio-pesquisa na formação do professor-pesquisador e seus fundamentos. In: BARBOSA, R. L. L. (Org.). Formação de educadores: artes e técnicas - ciências e políticas. São Paulo: UNESP, 2006

GHEDIN, Evandro, OLIVEIRA, Elisangela S. de; ALMEIDA, Whasgthon A. de Almeida. Estágio com pesquisa. São Paulo: Cortez, 2015.

GIMENES, Camila Itikawa, O Programa Institucional de Bolsa de Iniciação à Docência (PIBID) e a formação de professores de Ciências Naturais: possibilidade para a práxis na formação inicial?. São Paulo: Faculdade de Educação da Universidade de São Paulo, 2016. Disponível em http://flacso.org.br/files/2017/07/CAMILA_ITIKAWA_GIMENES.pdf. Acesso em 03 de janeiro de 2020.

GRANVILLE, M. A. (Org.). Teorias e práticas na formação de professores. In: Sala de aula: ensino e aprendizagem. 2. ed. Campinas: Papirus, 2008. p. 67.

HABERMAS, J. (1982). Conocimiento e interés. Madrid: Taurus Ediciones, S. A. (Trabalho original em alemão publicado em 1968).

LISTON, D. P., ZEICHNER, K. M. Teacher education and the social conditions of schooling. New York, NY: Routledge, 1991.

PIMENTA, Selma Garrido; LIMA, Maria do Socorro Lucena. Estágio e Docência. 7. a ed. São Paulo. São Paulo. Cortez, 2014.

PIMENTA, Selma Garrido; LIMA, Maria do Socorro Lucena. Estágios supervisionados e o Programa de Bolsa de Iniciação à Docência: duas faces da mesma moeda?. Revista Brasileira de Educação, v 24. 2019.

SARAVIA, L. M. La formación inicial docente. In: SARAVIA, L. M.; FLORES, I. La formación de maestros en América Latina: estudio realizado en diez países. Peru: Ministerio de Educación, DINFOCAD, PROEDUCA-GTZ, 2005.

SARAVIA, L. M.; FLORES, I. La formación de maestros en América Latina: estúdio realizado en diez países. Peru: Ministerio de Educación, DINFOCAD, PROEDUCAGTZ, 2005.

SILVESTRE, Magali aparecida; PLACCO, Vera Maria Nigro de Sousa. Modelos de formação e estágios curriculares, Revista Brasileira de Pesquisa sobre Formação Docente, v 5, n. ${ }^{\circ}$ 5, agos/dez. 2011. Disponível em https://revformacaodocente.com.br/index.php/rbpfp/article/view/44/34. Acesso em $27 \mathrm{de}$ dezembro de 2020. 
ZEICHNER, K. M. Políticas de formação de professores nos Estados Unidos: como e por que elas afetam vários países no mundo. Tradução de Cristina Antunes. Belo Horizonte: Autêntica Editora, 2013.

\section{Agradecimentos}

Agradecimentos ao apoio da Fundação de Apoio à Pesquisa do Estado do Amazonas (FAPEAM) e à Coordenação de Aperfeiçoamento de Pessoal de Nível Superior (CAPES).

\section{SOBRE OS AUTORES:}

\section{Evandro Ghedin}

Professor Titular-Livre da Faculdade de Educação da Universidade Federal do Amazonas (UFAM). Possui Pós-doutorado em Didática pela Faculdade de Educação da USP (2010). É Doutor em Filosofia da Educação pela USP (2004). Mestre em Educação pela UFAM (2000). Especialista em Antropologia da Amazônia pela UFAM. Especialista em Filosofia e Existência pela Universidade Católica de Brasília (UCB). Graduado em Filosofia pela UCB (1995). Professor Permanente no PPGECEM - Rede Amazônica de Educação em Ciências e Matemática (REAMEC). Professor Permanente no PPGE-UFAM. Professor Permanente no PGEDA - Doutorado em Educação na Amazônia - EDUCANORTE. Tem experiência na área de Educação, com ênfase em Educação em Ciências, atuando principalmente nos seguintes temas: Didática e Formação de Professores; Metodologia da Pesquisa em Educação; Epistemologia; Educação em ciências; Filosofia da Educação. Atuou na Educação Básica da Rede Pública e Privada por 5 anos. E-mail: evandroghedin@ufam.edu.br

(iD) http://orcid.org/0000-0002-2844-6122

\section{Maria Leogete Joca da Costa}

Doutoranda em Educação pela Universidade Federal do Amazonas (UFAM); Professora da Universidade Federal de Roraima (UFRR), Brasil; Integrante do Laboratório de Neurodidática e Formação de Professores; E-mail: maria.leogete@ufrr

iD https://orcid.org/0000-0002-4485-3561

\section{Patrik Marques dos Santos}

Doutorando em Educação em Ciência e Matemática no Programa de Pós-Graduação em Educação em Ciências e Matemática da Rede Amazônica em Educação em Ciências e Matemática (Reanec); Professor no Instituto Federal de Educação, Ciências e Tecnologia do Amazonas (IFAM) - Brasil; E-mail: patrik.santos@ifam.edu.br

iD https://orcid.org/0000-0001-5105-4891 